\title{
sciendo
}

\section{Comparative analysis of stock selection using a hybrid MCDM approach and modern portfolio theory}

\author{
Marija Vuković \\ University of Split, Faculty of Economics, Business and Tourism, Croatia, \\ marija.vukovic@efst.hr \\ Snježana Pivac \\ University of Split, Faculty of Economics, Business and Tourism, Croatia, \\ snjezana.pivac@efst.hr \\ Zoran Babić \\ University of Split, Faculty of Economics, Business and Tourism, Croatia, \\ babic@efst.hr
}

\begin{abstract}
The problem of selecting an optimal set of investment stocks is of a huge interest for both individual and institutional investors. This paper compares the hybrid multiple criteria decision making (MCDM) approach to selecting the best stock to invest in, with the stock selection using modern portfolio theory (MPT). When selecting stocks, it is very important to thoroughly analyse stocks, according to multiple criteria, including their equity market indicators, as well as financial indicators. The objective of the research is to compare the stock selection using a hybrid MCDM approach and MPT, which includes only the equity market indicators. The analysed sample includes 18 stocks, which are CROBEX components on the Croatian capital market from January 2017 to January 2019. The rankings of stocks were calculated using five MCDM methods. These were then used to obtain the final hybrid stock ranking, which was compared to the MPT stock selection. The results show that there is a significant difference in the stock rankings. However, the stocks which have not entered any portfolio in MPT selection were ranked as lowest according to the hybrid MCDM approach, which confirms that those stocks are the worst to invest in. The research can serve as a guidance for investors to use all available stock information in their decision making process of investment.
\end{abstract}

Keywords: MCDM approach, modern portfolio theory, stock selection.

JEL classification: C44, C52, G11.

DOI: $10.2478 /$ crebss-2020-001 1

Received: October 15, 2020

Accepted: December 2, 2020 


\section{Introduction}

The problem of choosing the right set of stocks to invest in is very important for all investors. When selecting the stocks, investors must analyse stocks through multiple criteria, including the equity market indicators, as well as the financial indicators. While the equity market indicators contain the information about a stock's performance, such as the mean return, total risk, systematic risk etc., the financial indicators show the company's performance and the insight into its financial situation (Marasović, Babić, 2011). Therefore, it is important to take both financial and equity market indicators into consideration when selecting a set of investment stocks.

Markowitz (1959) has developed the first model for portfolio optimization in 1952 , setting the basis for the modern portfolio theory (MPT). His model takes only two criteria into consideration: return and risk (Markowitz, 1959), where the risk is measured by the variance of returns distribution. His idea was to show the calculation of a portfolio with the highest expected return for a given level of risk, or the lowest risk for a given level of expected return (Marasović, Babić, 2011).

Since the stock selection decision making process includes multiple stocks and more than one criterion, it can be viewed as a multiple criteria decision making (MCDM) problem (Poklepović, Babić, 2014). Many MCDM methods have been developed through time, and based on the usage of different MCDM methods in the field of stock selection, this paper analyses the ranking of stocks by five selected MCDM methods with cardinal features of information, including multiple attribute utility theory (MAUT) and outranking methods (Zavadskas, Turskis, 2011, Podvezko, 2011 ). Those methods include: Simple Additive Weighting (SAW), Technique for Order Preference by Similarity to Ideal Solution (TOPSIS), Linear assignment method, Preference Ranking Organization Method for Enrichment Evaluation (PROMETHEE) and Complex proportional assessment method (COPRAS) (Bernardo, Blin, 1977, Kou et al., 2012, Poklepović, Babić, 2014, Ginting et al., 2017). Since those methods can yield different results of the rankings, a hybrid stock ranking is calculated.

Therefore, the aim of this paper is to compare the stock rankings using the hybrid MCDM approach with the rankings obtained by MPT. In this way, it can be determined if there are differences in stock selection, from the sample of the same stocks, when multiple criteria are considered, compared to the stock selection by only two criteria according to Markowitz's theory. For appropriate stock selection, investors in practice often use limited information, usually the risk and return values. Using other relevant financial information leads to different investment decision, especially when considering the stocks which are not ranked as the highest or the lowest. This paper provides empirical evidence and confirms that in most investment decision making it is appropriate to use more available financial information.

\section{Literature Review}

As it has been previously mentioned, the first model for portfolio optimization was developed in 1952 by Markowitz. His model proposed the return and risk as the only two criteria considered when selecting a portfolio (Markowitz, 1959, Xidonas, Mavrotas, Psarras, 2009, Marasović, Babić, 2011). However, this model has been criticized for that reason, since there are many other indicators, besides risk and return, which are important for portfolio selection. It is a multidimensional problem, since the decision making in reality is rarely based on only one or two criteria (Zopounidis, Doumpos, 2002). Therefore, multiple criteria should be considered in the 
portfolio selection, which makes it a multiple criteria problem (Marasović, Babić, 2011 , Poklepović, Babić, 2014).

MCDM provides a very broad spectrum of methodological approaches for effectively addressing the problem of portfolio selection (Xidonas, Mavrotas, Psarras, 2009). However, different MCDM methods have different aspects of evaluation, so they can produce divergent rankings of alternatives. Kou et al. (2012) concluded that a hybrid approach, based on Spearman's rank correlation coefficient, can provide a compatible ranking when different MCDM techniques disagree.

Hsu (2014) analysed Taiwan's 62 listed opto-electronics companies and combined their financial and risk evaluation indicators. Then the companies were divided into low, moderate and high-risk groups using grey clustering analysis and business performance evaluation and sorting of each grouping was obtained by Vlse Kriterijumska Optimizacija Kompromisno Resenje (VIKOR) method combined with the grey entropy weighting method. Hatami-Marbini and Kangi (2017) presented a group MCDM framework for selecting undervalued stocks using financial ratios and subjective judgments of experts in financial markets. They developed three versions of fuzzy TOPSIS to determine a ranking order of the companies and then calculated Spearman's rank correlation coefficient, which indicated strong similarity between the rankings of the three methods proposed. Vetschera and Almeida (2012) focused on portfolio selection based on outranking methods, specifically the Preference Ranking Organization Method for Enrichment Evaluation (PROMETHEE) method. They concluded that PROMETHEE ranking of all boundary portfolios can be performed for smaller problems and that it provides a close approximation of the total ranking. Fazli and Jafari (2012) used VIKOR method to select the best alternatives for investment in Tehran stock exchange and concluded that only 2 out of 50 companies were qualified for investment. They also found that return on equity is the most important criterion in stock selection. According to Marqués, García and Sánchez's review (2020) of MCDM models in financial management applications, the most commonly used MCDM methods in portfolio management, regarding stocks and investment, are TOPSIS, VIKOR, ELECTRE and PROMETHEE methods. Mitkova and Mlynarovič (2007) compared the rankings of pension funds in Slovakia by using PROMETHEE method with the rankings obtained through applications of modern portfolio theory. They found that in spite of the different approaches, the results are rather similar.

As for Croatian capital market, Marasović (2009) highlighted the problem of comparability of stocks from different sectors according to particular criteria. Therefore, Marasović and Babić (2011) presented a two-step multi-criteria model which considers specific features of industries and the market's different perceptions of prospects for different industries in the optimal portfolio selection using the data from Zagreb Stock Exchange. Poklepović and Babić (2014) obtained the rankings of 19 stocks by nine criteria on the Zagreb Stock Exchange in the period from March 2012 to March 2014. They used hybrid ranking with and without taking the industry into consideration, and concluded that the worst stocks to invest in are the same in both scenarios, while the best stocks to invest are slightly different between the two scenarios.

As it can be seen, most of the research in the field of finance and stock selection by MCDM methods, used one or a few MCDM methods. However, those research often lack the comparison of more methods to test if they perform similarly. This research relies mostly on Poklepović and Babić (2014), using a hybrid MCDM approach, to examine whether these developed MCDM methods give similar rankings of stocks from Zagreb Stock Exchange. Later on, the work was extended with the comparison with the first and the simplest model of portfolio optimization, i.e. 
the Markowitz model, in order to check for potential differences in the rankings obtained by the traditional method and more encompassing methods.

\section{Research Methodology Data}

The analysed sample includes the daily data of 18 stocks, which are CROBEX components on the Croatian capital market, in the period from January 2017 to January 2019. The data, which included the information about the stock price and the traded volume, was obtained from Zagreb Stock Exchange database (Zagreb Stock Exchange, 2019), and it was used to calculate the indicators of a stock performance. Those indicators include the mean return, risk of a stock (measured by standard deviation of the mean returns) and systematic risk (beta) (Marasović, Babić, 2011). Average daily traded volume was calculated from the daily volumes.

Besides those equity market indicators, the financial statements of the relevant companies were used to calculate some of the most important financial indicators from companies' financial statements for 2018, which are relevant to investors in their decision making. Those indicators include (Arkan, 2016, Astuty, 2017): earnings per share (EPS), return on equity (ROE), price to book value ratio $(P / B)$, price to sales ratio $(\mathrm{P} / \mathrm{S})$ and return on assets (ROA).

All of these indicators were used as criteria for the decision making of the stock investment for 18 chosen stocks. The initial data is shown in Table 1. The 18 stocks represent the alternatives ( $A 1$ to $A 18)$ and the indicators represent the criteria $(C 1$ to C9) for MCDM process. However, since some of the criteria have negative values, they were translated for the purpose of calculation. Specifically, for each criteria with negative values in Table 1, minimum was calculated, which was then subtracted from each value in a particular column. For the criteria with all positive values, nothing was changed (Poklepović, Babić, 2014).

Table 1 Initial data

\begin{tabular}{|c|c|c|c|c|c|c|c|c|c|c|}
\hline & \multirow[b]{2}{*}{ Stock } & $\begin{array}{c}\text { Mean } \\
(\%)\end{array}$ & $\begin{array}{c}\text { Std. dev. } \\
(\%)\end{array}$ & Volume & Beta & EPS & $\begin{array}{l}\text { ROE } \\
(\%)\end{array}$ & $\mathrm{P} / \mathrm{B}$ & $\mathrm{P} / \mathrm{S}$ & $\begin{array}{c}\mathrm{ROA} \\
(\%)\end{array}$ \\
\hline & & $\mathrm{Cl}$ & C2 & C3 & C4 & C5 & C6 & C7 & $\mathrm{C} 8$ & C9 \\
\hline Al & ADPL & 0.2137 & 2.19 & 1382.93 & 0.51 & 16.72 & 9.36 & 0.95 & 0.66 & 5.20 \\
\hline A2 & ADRS2 & -0.1037 & 1.94 & 2302.18 & 0.68 & 55.08 & 3.63 & 0.28 & 0.67 & 1.90 \\
\hline A3 & ARNT & -0.3592 & 2.67 & 864.13 & 0.37 & 17.17 & 5.63 & 1.47 & 3.24 & 3.29 \\
\hline A4 & ATGR & 0.2753 & 3.06 & 420.82 & 1.12 & 82.84 & 12.28 & 1.28 & 0.54 & 5.39 \\
\hline A5 & ATPL & 1222 & 5.90 & 762.22 & 0.06 & 58.38 & 14.42 & 1.58 & 2.44 & 5.70 \\
\hline A6 & DDJH & -1.2446 & 7.06 & 4504.48 & 0.68 & -3.29 & -38.62 & 2.29 & 0.38 & -5.35 \\
\hline A7 & DLKV & -0 & 5.65 & 10656 & 42 & 0 & 5.23 & 1.98 & 0.32 & 0.94 \\
\hline A8 & NTT & & 2.69 & & 0.70 & 50. & 28.82 & 6.81 & 08 & 8.26 \\
\hline A9 & HT & & 0 & 6 & 0.46 & & 6.40 & 1.07 & .74 & 5.11 \\
\hline A 10 & INGR & & 5.22 & 131 & & O. & 12.02 & 0.46 & 0.72 & 1.50 \\
\hline Al1 & $\mathrm{El}$ & $-c$ & 2. & & 0.81 & 42. & 4.35 & 0.74 & 0.65 & 2.91 \\
\hline $\mathrm{A} 12$ & KRAS & -0 & 2.44 & 194 & 0.79 & 22.17 & 4.57 & 0.95 & 0.62 & 2.51 \\
\hline A13 & MAIS & 81 & 2.79 & 311.65 & 1.33 & 14.82 & 10.33 & 1.95 & 2.78 & 5.50 \\
\hline A 14 & OPTE & -0.4341 & 5.26 & 28452.85 & 1.18 & -0.85 & -303.61 & 9.70 & 0.38 & -8.96 \\
\hline A15 & PODR & -0.0184 & 2.54 & 1419.53 & 1.03 & 3.35 & 0.82 & 0.66 & 0.47 & 0.47 \\
\hline A16 & RIVP & -0.0424 & 2.66 & 31328.13 & 0.70 & 1.94 & 9.74 & 2.19 & 3.14 & 4.91 \\
\hline Al7 & LEN & -0.4791 & 8.55 & 25731.26 & 1.87 & 2.18 & 14.86 & 0.94 & 0.48 & 9.08 \\
\hline A 18 & ZABA & -0.0144 & 3.73 & 6927.05 & 1.47 & 3.26 & 5.76 & 0.93 & 3.11 & 0.82 \\
\hline Crite & type & $\max$ & $\min$ & $\max$ & $\min$ & $\max$ & $\max$ & $\min$ & $\min$ & $\max$ \\
\hline
\end{tabular}

Source: Authors' calculation according to the data from Zagreb Stock Exchange. 


\section{Methods}

This paper uses MPT and MCDM approach in stock selection in order to compare the obtained rankings. As mentioned, MPT uses only the return and risk of a stock as criteria for decision making in portfolio selection, and it does not allow for additional criteria, which is the main reason why it has endured many criticisms (Markowitz, 1959, Xidonas, Mavrotas, Psarras, 2009, Marasović, Babić, 2011, Aouni et al., 2018). On the other hand, MCDM refers to making decisions according to multiple, usually conflicting, criteria. Since investment decision making constantly becomes more complex, this is a real problem, because many additional criteria exist and are increasing in number and importance (Poklepović, Babić, 2014, Aouni et al., 2018). Many MCDM methods have been developed, but all of them share the characteristics of dealing with multiple attributes, conflicting criteria and incompatible units (Poklepović, Babić, 2014). The main role in MCDM belongs to the decision maker, who cannot be replaced by any method. Those methods can be used as a guideline for potential improvement of the decisions which are made, but they cannot determine the best solution by themselves (Poklepović, Babić, 2014).

Since MCDM methods can produce different rankings of alternatives, a hybrid approach, based on Spearman's rank correlation coefficient, is proposed, since it combines all of the MCDM methods. That way the optimal solution can be reached (Kou et al., 2012).

The weights for each criterion used in MCDM approach were obtained by the Analytic Hierarchy Process (AHP) method. According to previously research, additionally in January 2019, 15 academics from the field of finance, from University of Split, Faculty of Economics, Business and Tourism and 15 experts employed directly in investment companies and credit institutions engaged in investment consulting in Croatia were consulted. Their assessments were rather uniform with minimum variance and representative mean values are taken. AHP is a multicriteria decision making approach, based on pairwise comparisons, which relies on the judgements of experts to obtain priority scales. Weight coefficients for each element are determined through mutual comparisons and their sum is equal to one, which allows the decision maker to arrange the elements in a hierarchic structure in terms of importance (Saaty, 2008).

Criteria weights can be seen in Table 2. They were used for calculation of the stock rankings for each of the five selected MCDM methods.

Table 2 Weights for each criterion obtained by the AHP method

\begin{tabular}{|c|c|c|c|c|c|c|c|c|c|}
\hline & $C 1$ & $C 2$ & $C 3$ & $C 4$ & $C 5$ & C6 & C7 & C8 & C9 \\
\hline $\mathrm{w}_{\mathrm{j}}$ & 0.0370 & 0.0189 & 0.0533 & 0.0259 & 0.2182 & 0.3070 & 0.0764 & 0.1543 & 0.1089 \\
\hline
\end{tabular}

Source: Authors' calculation.

MCDM methods used in this research were: Simple Additive Weighting (SAW), Technique for Order Preference by Similarity to Ideal Solution (TOPSIS), Linear assignment method, Preference Ranking Organization Method for Enrichment Evaluation (PROMETHEE) and Complex proportional assessment method (COPRAS).

Simple Additive Weighting (SAW) method is one of the most frequently used MCDM methods. Firstly, each criterion (attribute) in this method is assigned an importance weight. Afterwards, the weights of each criterion become the coefficients of the variables in the decision matrix, so the total score for each alternative is obtained by multiplying the data from the decision matrix for each attribute by the weight of that attribute. Summing the products across all attributes 
gives a final rating of each alternative, where the highest-scoring alternative is the one proposed to the decision maker (Poklepović, Babić, 2014).

Technique for Order Preference by Similarity to Ideal Solution (TOPSIS) method is based on identifying an alternative which is closest to the ideal solution and furthest to the negative ideal solution in a multi-dimensional computing space. Therefore, the best-chosen alternative not only has the shortest distance from the ideal positive solution, but also has the longest distance from the negative ideal solution. It considers the distances to both solutions simultaneously by taking relative closeness to the ideal solution (Velasquez, Hester, 2013, Poklepović, Babić, 2014, Ginting et al., 2017).

The linear assignment method is based on a set of rank alternatives by attribute with a given set of criteria weights. Only the comparisons among the elements of the decision matrix are used as input to the process itself, rather than the actual data. Alternatives are then ranked from best to worst by each criterion, and then the rankings for each alternative are summed up to get the final ranking (Bernardo, Blin, 1977).

The Preference Ranking Organization Method for Enrichment Evaluation (PROMETHEE) choose the best alternatives by using pairwise comparisons and outranking relationships. The final selection is based on the positive and negative preference flows of each alternative. The positive preference flow indicates how an alternative is outranking all the other alternatives and the negative preference flow indicates how an alternative is outranked by all the other alternatives (Kou et al., 2012).

Complex proportional assessment method (COPRAS) assumes direct and proportional dependences of the priority and utility degree of the alternatives under the presence of conflicting criteria. It determines a solution with the ratio to the ideal solution and the ratio to the anti-ideal solution. The degree of utility is determined by comparing the analysed alternatives with the best one (Poklepović, Babić, 2014).

Finally, Spearman's rank correlation coefficients between five different methods were calculated and used as the starting point for the calculation of the weights and normalized weights of each individual MCDM method, which were then used to obtain the final hybrid stock ranking.

Stocks were also ranked by MPT. Firstly, the task was to find what percent of each individual stock should be in a portfolio in order to get the highest expected return for a given level of risk, and nine portfolios were obtained. After the analysis according to MPT, the stocks were ranked depending on how many portfolios they have entered. Since some of the stocks have entered the same number of portfolios, and some of them have entered none of the portfolios, mean ranks were used for those stocks.

\section{Results and Discussion}

As it can be seen from Table 3, most of the stock rankings are similar, no matter which MCDM method was used. However, some differences can be seen in the rankings obtained by the Linear assignment method.

In order to check the correlation between the 18 chosen stocks (alternatives), Spearman's rank correlation coefficients between all selected MCDM methods were calculated and they are shown in Table 4. The weights and normalized weights of all methods are shown in Table 5. They are all very similar, except for the linear assignment method, which has a significantly lower weight than the other methods. This confirms the significant differences between the linear assignment method 
rankings and other four MCDM methods, which is also visible through Spearman's rank correlation coefficients.

Table 3 Results of the rankings using five selected MCDM methods

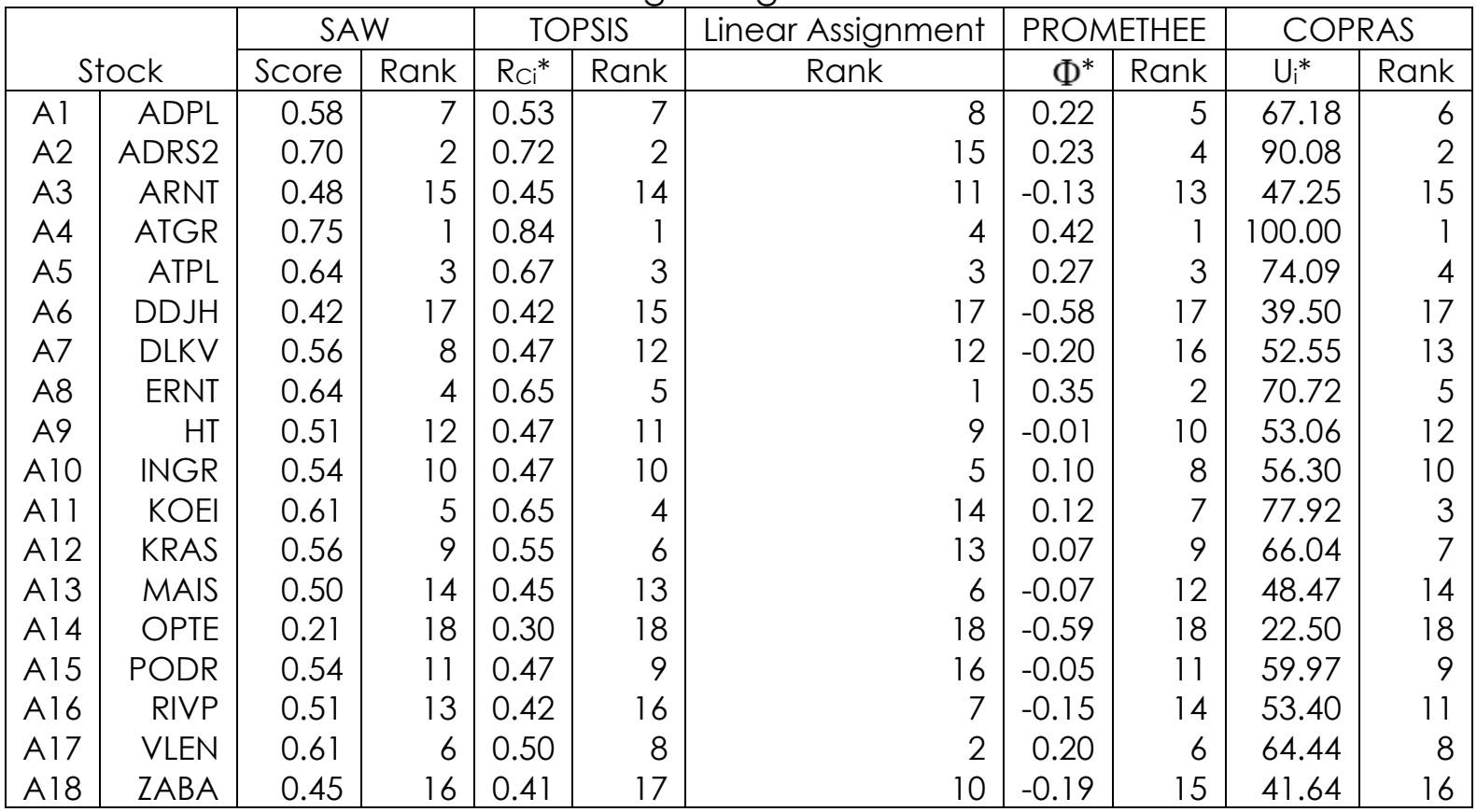

*Note: Rci - Relative closeness; $\Phi$ - Net flow; $U_{i}-$ Quantitative utility

Source: Authors' calculation.

Table 4 Spearman's rank correlation coefficients between selected MCDM methods

\begin{tabular}{|l|r|r|r|r|r|}
\hline & \multicolumn{1}{|c|}{ SAW } & \multicolumn{1}{c|}{ TOPSIS } & Linear Assignment & PROMETHEE & COPRAS \\
\hline SAW & 1 & & & & \\
TOPSIS & $0.9463^{* *}$ & 1 & & & \\
Linear Assignment & 0.4551 & 0.3292 & 1 & & \\
PROMETHEE & $0.8989^{* *}$ & $0.9195^{* *}$ & $0.6017^{* *}$ & 1 & \\
COPRAS & $0.9505^{* *}$ & $0.9608^{* *}$ & $0.3725^{* *}$ & $0.9195^{* *}$ & 1 \\
\hline
\end{tabular}

**significant at 0.01 level

Source: Authors' calculation.

Table 5 Weights and normalized weights

\begin{tabular}{|l|c|c|r|r|r|}
\hline & SAW & TOPSIS & Linear Assignment & PROMETHEE & COPRAS \\
\hline Weights & 0.8127 & 0.7890 & 0.4396 & 0.8349 & 0.8008 \\
Normalized weights & 0.2210 & 0.2146 & 0.1196 & 0.2271 & 0.2178 \\
\hline
\end{tabular}

Source: Authors' calculation.

Based on the rankings of the alternatives (stocks), according to all five selected MCDM methods and their normalized weights, a hybrid final ranking of the alternatives was calculated (Table 6). A4 (ATGR) proved to be the best stock, as expected, since four out of five methods ranked it at the first place. The following best stocks are stocks A5 (ATPL), A8 (ERNT) and A2 (ADRS2), which were also highly ranked by all methods. The worst stock to invest in is Al4 (OPTE), which was expected, considering it was ranked as the worst by all of the MCDM methods, and A6 (DDJH) was second last by all methods, as well as by hybrid ranking.

Comparing these rankings with the initial data and the criteria weights by relevance for shareholders, the stock ranking is completely logical. Specifically, A14 and A6 stocks have some negative indicators, primarily ROE and EPS, which 
represent the criteria with the highest weights. On the other hand, A4 and A5 have very high ROE and EPS, and none of their indicators (criteria) have negative values, while A8 and A2 also have very high relevant indicators, but they have negative average returns, which ranked them somewhat lower than the previous two stocks.

Table 6 also shows the stock rankings by MPT. It can be seen that ATGR has entered nine portfolios, followed by ADPL with eight. Therefore, those stocks are the highest ranked according to MPT. On the other hand, seven stocks share the lowest rank, because they have not entered any portfolio. Comparing the rankings, it can be seen that, despite some differences, the highest and the lowest ranked stocks are the same, regardless of the ranking method.

Table 6 Comparison of the final hybrid ranking and MPT ranking of the stocks

\begin{tabular}{|l|r|r|r|r|r|}
\hline \multicolumn{2}{|c|}{ Stock } & \multicolumn{2}{|c|}{ Final hybrid ranking } & \multicolumn{2}{c|}{ MPT ranking } \\
\cline { 2 - 6 } & Score & Rank & Number of portfolios & Rank \\
\hline A1 & ADPL & 6.4477 & 7 & 8 & 2 \\
A2 & ADRS2 & 4.0084 & 4 & 0 & 15 \\
A3 & ARNT & 13.8531 & 15 & 2 & 8 \\
A4 & ATGR & 1.3587 & 1 & 9 & 1 \\
A5 & ATPL & 3.2178 & 2 & 4 & 4 \\
A6 & DDJH & 16.5709 & 17 & 0 & 15 \\
A7 & DLKV & 12.2419 & 12 & 0 & 15 \\
A8 & ERNT & 3.6196 & 3 & 0 & 15 \\
A9 & HT & 10.9726 & 11 & 3 & 6 \\
A10 & INGR & 8.9481 & 9 & 4 & 4 \\
A11 & KOEI & 5.8800 & 6 & 1 & 10.5 \\
A12 & KRAS & 8.3990 & 8 & 1 & 10.5 \\
A13 & MAIS & 12.3748 & 13 & 4 & 4 \\
A14 & OPTE & 18.0000 & 18 & 0 & 15 \\
A15 & PODR & 10.7331 & 10 & 2 & 8 \\
A16 & RIVP & 12.7178 & 14 & 2 & 8 \\
A17 & VLEN & 6.3865 & 5 & 0 & 15 \\
A18 & ZABA & 15.2701 & 16 & 0 & 15 \\
\hline
\end{tabular}

*Note: For the stocks with the same number of portfolios, mean ranks were calculated. Source: Authors' calculation.

In order to explore whether these rankings obtained by MPT are MCDM methods are correlated, Spearman's rank correlation coefficient was calculated between the rankings of MPT and the hybrid MCDM rankings.

Table 7 Spearman's rank correlation coefficients between hybrid ranking and modern portfolio theory ranking

\begin{tabular}{|r|r|r|}
\hline & Hybrid rank & Modern portfolio theory rank \\
\hline Hybrid rank & 1 & \\
Modern portfolio theory rank & 0.292 & 1 \\
\hline
\end{tabular}

Source: Authors' calculation.

The results can be seen in Table 7. The correlation is not statistically significant. Therefore, it can be concluded that there are significant differences in the stock rankings obtained by different methods.

\section{Conclusion}

The problem of finding the optimal portfolio has existed since the existence of the market, and the biggest challenge is the fact that the market is not static and 
something that is valid today does not have to, and most likely will not be valid tomorrow. Successful investors know that there is no perfect portfolio. However, it is important to have various models available, by which investors can form a portfolio that will satisfy their willingness to achieve a certain satisfactory return with a certain level of risk.

In this paper, by comparing two models, the older one with risk and return as variables included in the model (MPT) and the newer hybrid MCDM model with more variables. The results of previous research (Mitkova, Mlynarovič, 2007, Fazli, Jafari, 2012, Vetschera, Almeida, 2012, Hsu, 2014, Hatami-Marbini, Kangi, 2017) have often used portfolio selection by using only one chosen method, while the research that used the comparison of several methods and financial indicators have shown similar results. However, this research has shown that the similar results of stock rankings refer only to the highest and the lowest ranked stocks. Differences exist in the MPT approach and the approach which uses a larger number of relevant financial indicators for a broad spectrum of the middle ranked stocks. Since investors are not a priori able to know if their decision is optimal, a post-hoc analysis can be conducted in order to analyse the return of investment for each stock after the period of investment. Since investors have to rebalance their portfolios sometimes to a weekly or daily basis, and since they might have preference for investing not only in the highest ranked stock, but also in some of the middle ranked stocks, this research can encourage them to use all available information.

It is important to emphasize that for investors, all investment information and the mathematical model, whichever they choose in their portfolio selection, will serve as an auxiliary tool in decision making, assuming that the investor is a real investor in the sense defined by Graham (Graham, Zweig and Buffet, 2003). The real investor is the one who will use careful analysis to invest his funds in a capital market driven by investment rather than speculative motives.

In addition, recent research show that the investment decision is not influenced only by the financial and market indicators, but by numerous behavioural factors (Statman, 2014). Therefore, further research should also take these factors into consideration in the investment decision making. Namely, certain anomalies appear on the market that refute the theory of the efficient market and rational investor, which is enough to set a mathematical model, but investors' decisions are influenced by certain psychological elements, as well as emotions and personality traits (Statman, 2014). Therefore, it is necessary to include behavioural factors, which influence investor decisions, as well as the movements in the capital market. As for mathematical models, further research in this area can include the comparison of stock rankings in different economic situations, as well the comparison of hybrid MCDM and MPT stock rankings with taking the industry of the particular stock into consideration.

\section{References}

1. Aouni, B., Doumpos, M., Pérez-Gladish, B., Stever, R. E. (2018). On the increasing importance of multiple criteria decision aid methods for portfolio selection, Journal of the Operational Research Society, Vol. 69, No. 10, pp. 1525-1542.

2. Arkan, T. (2016). The Importance of Financial Ratios in Predicting Stock Price Trends: A Case Study in Emerging Markets. Finanse, Rynki Finansowe, Ubezpieczenia, Vol. 1, No. 69, pp. 13-26.

3. Astuty, P. (2017). The Influence of Fundamental Factors and Systematic Risk to Stock Prices on Companies Listed in the Indonesian Stock Exchange. European Research Studies Journal, Vol. XX, No. 4A, pp. 230-240. 
4. Bernardo, J. J., Blin, J. M. (1977). A Programming Model of Consumer Choice Among MultiAttributed Brands. Journal of Consumer Research, Vol. 4, No. 2, pp. 111-118.

5. Fazli, S., Jafari, H. (2002). Developing a hybrid multi-criteria model for investment in stock exchange. Management Science Letters, Vol. 2, No. 2, pp. 457-468.

6. Ginting, G., Fadlina, M., Siahaan, A. P. U., Rahim, R. (2017). Technical Approach of TOPSIS in Decision Making. International Journal of Recent Trends in Engineering \& Research, Vol. 3, No. 8, pp. 58-64.

7. Graham, B., Zweig, J., Buffett, W. (2003). The Intelligent Investor. Harper Collins Publishers, London.

8. Hatami-Marbini, A., Kangi, F. (2017). An extension of fuzzy TOPSIS for a group decision making with an application to Tehran stock exchange. Applied Soft Computing, Vol. 52, pp. 1084-1097.

9. Hsu, L. C. (2014). A hybrid multiple criteria decision-making model for investment decision making. Journal of Business Economics and Management, Vol. 15, No. 3, pp. 509-529.

10.Kou, G., LU, Y., Peng, Y., Shi, Y. (2012). Evaluation of classification algorithms using MCDM and rank correlation. International Journal of Information Technology \& Decision Making, Vol. 11, No. 1, pp. 197-225.

11.Marasović, B. (2009). Comparison of Optimal Portfolios Selected by Multicriterial Model Using Absolute and Relative Criteria Values. Investigacion Operacional, Vol. 30, No. 1, pp. 20-31.

12.Marasović, B., Babić, Z. (2011). Two-step multi-criteria model for selecting optimal portfolio. International Journal of Production Economics, Vol. 134, No. 1, pp. 58-66.

13.Markowitz, H. M. (1959). Porffolio Selection: Efficient Diversification of Investment. Yale UniversityPress, NewHaven, CT.

14.Marqués, A. I., García, V., Sánchez, J. S. (2020). Ranking-based MCDM models in financial management applications: analysis and emerging challenges. Progress in Artificial Intelligence, Vol. 9, pp. 171-193.

15.Mitková, V., Mlynarovič, V. (2007). A performance and risk analysis on the Slovak private pension funds market. Ekonomický časopis (Journal of Economics), Vol. 55, No. 3, pp. 232249.

16.Podvezko, V. (2011). The Comparative Analysis of MCDA Methods SAW and COPRAS. Inzinerine Ekonomika-Engineering Economics, Vol. 22, No. 2, pp. 134-146.

17.Poklepović, T., Babić, Z. (2014). Stock selection using a hybrid MCDM approach. Croatian Operational Research Review, Vol. 5, No. 2, pp. 273-290.

18.Saaty, T. L. (2008). Decision making with the analytic hierarchy process. International journal of services sciences, Vol. 1, No. 1, pp. 83-98.

19.Statman, M. (2014). Behavioral finance: Finance with normal people. Borsa Istanbul Review, Vol. 14, pp. 65-73.

20.Velasquez, M., Hester, P. T. (2013). An Analysis of Multi-Criteria Decision Making Methods. International Journal of Operations Research, Vol. 10, No. 2, pp. 56-66.

21.Vetschera, R., De Almeida, A. T. (2012). A PROMETHEE-based approach to portfolio selection problems. Computers \& Operations Research, Vol. 39, pp. 1010-1020.

22.Xidonas, P., Mavrotas, G., Psarras, J. (2009). A multicriteria methodology for equity selection using financial analysis. Computers \& Operations Research, Vol. 36, No. 12, pp. 3187-3203.

23.Zagreb Stock Exchange (2019). Regulated Market Store Overview. Available at: https://zse.hr/default.aspx?id=26495 [11 January 2019].

24.Zavadskas, E. K., Turskis, Z. (2011). Multiple criteria decision making (MCDM) methods in economics: an overview. Technological and Economic Development of Economy, Vol. 17, No. 2, pp. 397-427.

25.Zopounidis, C., Doumpos, M. (2002). Multi-criteria decision aid in financial decision making: methodologies and literature review. Journal of Multi-Criteria Decision Analysis, Vol. 11, pp. 167-186. 


\section{About the authors}

Marija Vuković, mag.oec. is a Teaching Assistant at the University of Split, Faculty of Economics, Business and Tourism, Department of Quantitative Methods. She currently teaches several statistical courses and attends postgraduate doctoral studies. She is a member of Croatian Operational Research Society, Croatian Statistical Association and American Statistical Association. Her main fields of interest are statistical methods in economics and business statistics. Author can be contacted at marija.vukovic@efst.hr.

Snježana Pivac, Ph.D. is a Full Professor at the University of Split, Faculty of Economics, Business and Tourism, Department of Quantitative Methods. She received her PhD in Quantitative Methods in Economics at the Faculty of Economics and Business Zagreb. She was the correspondent for Croatia for the International Federation of Operational Research Societies, the member of Croatian Operational Research Society, Croatian Statistical Association and American Statistical Association. Her main research interests are statistical methods in economics, business statistics, econometric modelling and actuarial mathematics. She is a Co-Editor of Croatian Operational Research Review (CRORR), ISSN 1848-0225. The author can be contacted at snjezana.pivac@efst.hr.

Zoran Babić, Ph.D. is a Professor Emeritus at the University of Split, Faculty of Economics, Business and Tourism, Department of Quantitative Methods. He was the vice dean for teaching and the head of the Department of Quantitative Methods. He was also the president of Croatian Operational Research Society and the editor of the first Croatian scientific journal in the field of operational research - Croatian Operational Research Review (CRORR). In addition, he is an Associate Editor of the European Journal of Operational Research - Central European Journal of Operations Research (CEJOR), published by Springer, which is the official journal of the operational research societies from Austria, Croatia, Czech Republic, Hungary, Slovakia and Slovenia. His main field of interest is multiple criteria decision making. The author can be contacted at babic@efst.hr. 